\title{
A RELAÇÃO DA LITERATURA DE CORDEL NA ANTROPONÍMIA DOS FANTOCHES POPULARES PORTUGUESES
}

\section{THE RELATION OF CHAPBOOKS IN THE ANTHROPONYMY OF THE PORTUGUESE POPULAR PUPPETS}

\author{
OLIVEIRA, José Luís de ${ }^{1}$
}

\begin{abstract}
RESUMO: O mundo do teatro de bonecos em Portugal está envolto numa bruma, devido, em parte, a algum desinteresse da classe teatreira, mas principalmente, à escassa documentação sobre esta arte ancestral. O teatro de marionetas popular era pouco palavroso, em oposição ao teatro de atores de carne e osso, onde o verbo era fundamental. O repertório de texto diminuto, transmitido por via oral, levou à perda substancial de um entretenimento que fez os encantos de miúdos e graúdos ao longo dos séculos. Uma das lacunas é a génese dos próprios apodos pelos quais os bonifrates eram conhecidos. Atualmente encontra-se vulgarizado o cognome Dom Roberto (conhecido até 1962 por robertos) para designar os bonecos de luva populares portugueses. Este evoluiu a partir do drama de cordel adaptado da lenda medieval Roberto do diabo e que fez parte do repertório do teatro de bonecos populares portugueses.
\end{abstract}

PALAVRAS-CHAVE: Teatro de bonecos, literatura de cordel, folhetos volantes.

ABSTRACT: The world of puppet theater in Portugal is shrouded in mist, partly due to some disinterest in theater professionals, but mainly due to the scarce documentation about this ancestral art. The popular puppet theater was of few text, as opposed to the actors theater, where the verb was fundamental. The diminutive repertoire of orally transmitted text has led to the substantial loss of entertainment that has made the charms of kids and adults over the centuries. One of the gaps is the

\footnotetext{
${ }^{1}$ Doutor em Artes Cénicas pela Universidade de Vigo. Professor Auxiliar Convidado na Universidade de Trás-osMontes e Alto Douro.
}

Jangada | nr. 10, jul/dez, 2017 | ISSN 2317-4722 - 4 | P á g i n a 
genesis of the nicknames for which puppets were known. At the moment the name Dom Roberto (known until 1962 by robertos) is popularized to designate the Portuguese glove popular puppets. This evolved from the chapbook drama adapted from the medieval legend Robert the devil and that was part of the repertoire of Portuguese popular puppet theatre.

KEYWORDS: Puppet theater, chapbooks.

O universo dos bonifrates ${ }^{2}$ em Portugal carece de um estudo que possa trazer-lhe o (re)conhecimento público desta arte primordial. A pouca informação existente requer o recurso a várias fontes que possam clarear a penumbra em que se encontra o teatro de marionetas em Portugal. A origem dos cognomes pelos quais eram conhecidas as marionetas e a evolução dessa antroponímia, levou à pesquisa documental para dar resposta às várias questões que o tema suscita. Encontramos na atualidade a denominação Dom Roberto para designar os fantoches populares portugueses. Surgenos, assim, uma primeira suposição para o estabelecimento desta terminologia, ligada a Roberto Xavier de Matos, um empresário de teatro. Gustavo de Matos Sequeira em Teatro de Outros Tempos aventa a hipótese de poder ter sido este empresário o responsável pela fixação do nome do boneco de luva português:

A Intendência Geral da Polícia, aí por volta dos primeiros anos do século passado, deu licença para funcionar, num palheiro do Pátio do Patriarca, a S. Roque, um teatrinho que dava pelo nome de Teatro Pinturesco e Mechanico. O que lá se representava não sei. O empresário ou empresários, em 1812, passou ou passaram a um tal Roberto Xavier de Matos, o Palheiro que se consagrara à arte de Talma. (...) As tais «figuras pinturescas», eram apresentadas por um refugiado espanhol, D. Simon Sadinos. Dois anos mais tarde, o imaginoso Matos que se entretivera a exibir fantoches (estará aqui a origem dos Robertos?) conseguiu organizar um grupo de amadores capitalistas ou, talvez melhor, de capitalistas amadores, obteve dos seus bolsinhos dois contos de réis, e entrou em contracto com um D.

\footnotetext{
${ }^{2}$ Palavra exclusivamente portuguesa para designar qualquer tipo de boneco ator, também conhecido por marioneta.
} Jangada | nr. 10, jul/dez, 2017 | ISSN 2317-4722 - 5 | P á g i n a 
Pedro de Loureda, administrador da casa da Marquesa de Niza a quem pertencia o palácio chamado, então, «do Patriarca» por nêle terem residido D. Tomaz de Almeida, o primeiro Patriarca de Lisboa, e D. José Manuel, o segundo, a-fim-de transformar o «Palheiro» dos bonecos e das vistas maquinadas num teatro digno de tal nome. (...) No fim de 1815 estava já de pé a nova Casa de Espectáculos (...) A companhia que inaugurou a nova casa de espectáculos era de curiosos e de actores (Sequeira, 1933, pp. 409-411).

Roberto Xavier de Matos era um empresário de teatro no geral, não exclusivamente dedicado a uma matéria única como o teatro de fantoches. Matos Sequeira começa por referir que no Pátio do Patriarca havia um "Teatro Pinturesco e Mechanico", o que nos sugere ter sido um teatrinho de autómatos, o qual Xavier de Matos viria a explorar durante dois anos. Contudo, o autor comenta não saber o que lá se representava, mas atendendo à própria designação de teatro mecânico e ao facto de que o "director ia estabelecer a máquina na sala do Pátio do Palácio Velho do Patriarca" compreender-se-á não se tratar de espetáculos com marionetas manipuladas ao vivo. Apesar disto, Gustavo Matos Sequeira questiona a possibilidade de a origem dos Robertos estar relacionada com a circunstância de que Roberto Xavier de Matos se “entretivera a exibir fantoches". A forma desprendida como exibia os fantoches vem demonstrar o lado puramente empresarial de Xavier de Matos, visto que "as tais «figuras pinturescas», eram apresentadas por um refugiado espanhol, D. Simon Sadinos”.

Voltemos, portanto, à razão que nos levou a mencionar Roberto Xavier de Matos e o seu pressuposto apadrinhamento do nosso bonifrate popular. Este empresário foi o responsável pela produção e exploração do "Teatro Pinturesco $e$ Mechanico" e mantém-se como produtor daquele tipo de entretenimento durante dois anos. Gustavo Matos Sequeira alvitra poder dever-se ao empresário oitocentista o surgimento dos Robertos. Poderá Xavier de Matos ao longo dos escassos dois anos como produtor daquele tipo de espetáculo ter obtido relevância tal no panorama do teatro de fantoches, para que o homenageassem, colocando o seu nome no intrépido boneco de luva? Consideramo-lo pouco provável. A sugestão de Matos Sequeira é, 
para nós, uma hipótese remota, a qual mantemos entre os parêntesis, em que o próprio a formulou.

Debrucemo-nos, por isso, sobre a segunda hipótese como possível génese para a denominação Roberto. Esta dever-se-á ao enorme sucesso obtido pelo drama de cordel Roberto do diabo. As origens da sua história levam-nos diretamente para a Normandia francesa, onde nasceu a fama de Roberto, o diabo. Esta remonta ao século XIII, época em que o ducado da Normandia foi reunido definitivamente ao reino de França. A lenda conheceu um sucesso contínuo, desde o romance em verso octossilábico escrito por um autor anónimo no fim do século XII ou início do XIII. O texto aparece transcrito em latim, na recolha de Étienne de Bourbon (entre $1250 \mathrm{e}$ 1261), este serve de mito fundador à narrativa histórica Chroniques de Normandie (finais do século XIII a inícios do XIV). Foi adaptado para a cena sob a forma de drama religioso intitulado Miracle de Nostre-Dame par personnages (1375), uma obra de duzentas e cinquenta e quatro quadras monorrimas, datando da primeira metade do século XIV, cujo conteúdo visava a difusão oral e fins didáticos. Este texto foi depois transformado em prosa, sendo o incunábulo publicado pela primeira vez em Lyon, a 7 de maio 1496, com o título Vie du terrible Robert le dyable (Gaucher, 1998, p. 153). Élisabeth Gaucher, no seu estudo intitulado La Vie du terrible Robert le dyable - Un exemple de mise en prose (1496), revela-nos o possível trajeto, desde o texto escrito à assimilação deste pelo povo e, consequente passagem para o teatro itinerante:

Avec le Dit, écrit par un clerc mais diffusé par des jongleurs pour l'édification du peuple et des bourgeois, commence le processus de vulgarisation. Si l'ouvrage publié en 1496 s'adresse encore à des ecclésiastiques et à des notables, essentiellement hommes d'affaires ou officiers de justice, il semble avoir touché aussi un public d'artisans et de marchands, les romans d'aventures commençant à apparaître démodés dans les milieux lettrés (Gaucher, 1998, p. 153).

Gaucher diz-nos que o texto escrito por um clérigo foi difundido pelos jograis para edificação do povo e da burguesia, começando, com isto, o processo de vulgarização. A instalação das hordas góticas em território romano teve uma 


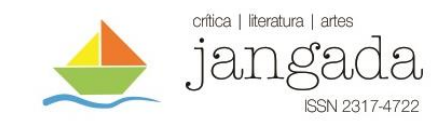

consequência importante sobre a natureza das representações teatrais. Desconhecedores da língua latina, os bárbaros jamais se poderiam interessar por espetáculos em que o elemento dramático se sobrepusesse ao visual. É assim que se criam condições muito favoráveis à rápida propagação do gosto pela observação de exibições de saltimbancos, de dançarinas, de artistas mímicos, de prestidigitadores, etc. Certamente que tais representações, pelo facto de se dirigirem mais à vista do que ao espírito, não deveriam possibilitar aos seus apresentadores a obtenção de um êxito sempre renovado. Assim, é que esses jograis adotavam uma vida essencialmente nómada. Esses artistas, que se deslocavam de terra para terra, de castelo para castelo, transportavam consigo não só animais amestrados como também máscaras e bonecos animáveis, através dos quais se preservaram algumas formas dramáticas tradicionais.

Continuemos, porém, com a viagem do texto Vie du terrible Robert le dyable para outras paragens. Os mercadores espanhóis, nas suas viagens entre Castela, França e a Flandres trouxeram-no para Espanha, onde foi traduzido e impresso em Burgos, em 1509, com o título La espantosa y maravillosa vida de Roberto el Diablo, asi al principio llamado, hijo del Duque de Normandía, el cual despues, por su santa vida, fue llamado Hombre de Dios (Baroja 1990: 384). A primeira edição portuguesa é de 1732, traduzida por Jeronymo Moreira de Carvalho (?-1748).

Lenda à parte, o homem D. Roberto I, sexto duque da Normandia, nasceu a 22 de junho de 1000 e morreu a 3 de julho de 1035, tendo chegado ao senhorio do ducado em 1027 ao suceder o seu irmão, que morreu prematuramente de forma misteriosa. Roberto "tê-lo-á envenenado" (Soares e Ferreira, 1996, p. 5383). A partir daí, fundou o seu império à força da espada, do fogo e da morte. Mas por fim arrependeu-se, e para cumprir a sua penitência foi fazer uma peregrinação a Jerusalém. No regresso veio a falecer em Nicéia (atualmente cidade de Iznik, na Turquia). Por tudo isto, D. Roberto recebeu os cognomes de "O Liberal”, "O Magnífico", ou "O Diabo". Foi, no entanto, esta última alcunha que o catapultou para os anais da literatura e do teatro. Todavia, estas duas artes substituíram o apodo Roberto, o Diabo, por outro, quiçá, mais ao gosto do público português criando o epíteto, Roberto do diabo, exposto na versão portuguesa de Jeronymo de Carvalho. Vejamos como este autor enuncia o título da obra: 
Historia do Grande Roberto, Duque de Normandia, e Imperador de Roma. Em que se trata da sua concepção, e nascimento, e de sua depravada vida, por onde mereceo ser chamado Roberto do diabo, e de seu grande arrependimento, e prodigiosa penitencia, por onde mereceo ser chamado Roberto de Deos, e prodigioso, que por mandado de Deos obrou em batalha (Carvalho, 1799, capa).

O autor português escreveu a preposição do a anteceder o cognome diabo, diferentemente, como podemos observar, nas versões francesa e espanhola, as quais precedem a alcunha, empregando o artigo definido masculino singular o. A designação Roberto, o Diabo, coloca o herói como sendo ele próprio a figura demoníaca, ao passo que Roberto do diabo permite assumir alguma inocência da personagem principal.

No Dicionário da Língua Portuguesa encontramos o substantivo diabo escrito com minúscula e maiúscula, respetivamente:

diabo s.m. pessoa má, perversa; pessoa astuta; pessoa irrequieta; criança turbulenta.

Diabo s.m. Religião, cada um dos anjos maus; espírito do mal; Demónio; Satanás (Costa et al., 2005, p. 550).

Consultámos, ainda, o Dicionário Etimológico da Língua Portuguesa, para confirmar o uso das duas grafias:

Diabo - s.m. Cada um dos anjos maus = SATANÁS; Génio do mal, espírito das trevas (Geralmente com inicial maiúscula) = DEMÓNIO, SATANÁS [figurado] Pessoa de mau génio ou de qualquer outra má qualidade. Pessoa feia. Pessoa astuta ou habilidosa. Criança turbulenta. Aparelhos das fábricas de tecidos. interj. Expressão que denota impaciência, ira, admiração, etc. fazer o diabo a quatro: causar grande rebuliço, confusão. Pobre diabo: pessoa insignificante . = Homúnculo, João-ninguém, Zé- ninguém; pessoa submissa ou sem iniciativa; pessoa com fracos recursos financeiros (Machado, 1995, p. 113). 
Neste dicionário é mencionado que o "espírito das trevas" é escrito "geralmente com inicial maiúscula", fazendo igualmente alusão à expressão "pobre diabo", referindo-se esta a uma "pessoa insignificante". O Génio do mal é, pois, grafado com maiúscula, sendo que a expressão de pobre diabo, utilizada para classificar um ser humano, é escrita com inicial minúscula. Com base nestas definições, podemos dizer que Jeronymo de Carvalho ao grafar a alcunha diabo com o grafema $\langle\mathrm{d}>$ minúsculo o aproxima do humano, o que de certa forma, o desliga do peso que a entidade sobrenatural maligna exerce na tradição cristã. E, se nos ativermos a esta designação de pessoa insignificante, torna-se mais clara a conotação que o autor, certamente, quis dar à personagem de Roberto, o da fragilidade do Homem perante as forças sobrenaturais. O mal é colocado em posição inferior à do bem, isto é, em português as duas entidades sobrenaturais têm o grafema $\langle d\rangle$ a iniciar o nome, contudo, Carvalho escreveu diabo com minúscula e deus com maiúscula.

No entanto, podíamos, ainda, resumir o facto de o autor setecentista escrever Roberto do diabo pela simples razão de Roberto ser filho do Diabo, e não o próprio Diabo. Vejamos um excerto do texto de Jeronymo de Carvalho:

E assim se deitárão ambos juntos, e estando em acto matrimonial, disse o Duque: Se fosse Deos servido, que agora gerássemos hum filho para socego do nosso Reino, e povo? A cujas palavras respondeo a Duqueza como desesperada: Concebesse eu, mais que fosse o diabo, e ao diabo offereço o que agora conceber. Caso estupendo! Desesperação fatal! Deshumana offerta! Mas que não fará o diabo, quando acha sujeita a materia? (...) Trouxe a Duqueza nas suas entranhas nove mezes o dito filho, e esteve de parto hum mez, e com tão grande perigo de vida que se julgou não escaparia; porém Deos a favoreceo tanto, que chegou a parir felizmente, e livrou do perigo, e todos julgárão ser este parto maravilhoso, e que incluía em si grande mysterio, como na verdade assim aconteceo (Carvalho, 1799, pp. 4-5).

Jangada | nr. 10, jul/dez, 2017 | ISSN 2317-4722 - 10 | 
Nesta breve passagem do texto, o Duque e a Duquesa estão "em acto matrimonial". E como o Diabo está em toda a parte, ouvindo as palavras desesperadas da Duquesa, ter-se-á aproveitado para usar o Duque como hospedeiro, para conceber o tal filho com ela, porque o “que não fará o diabo, quando acha sujeita a matéria?".

As cadeias de transmissão oral que ajudaram a difundir o nome desta personagem, têm assento garantido nas tradições de muitos povos, civilizações e continentes, levando a que ao longo destes séculos, que decorreram desde a criação da lenda oriunda da Normandia francesa, muitos tenham sido aqueles que contaram e recontaram esta história. Era comum os textos de grandes autores sofrerem adaptações e serem impressos em folhetos volantes, vendidos na rua:

Entretanto as tipografias lançam no mercado, em edições populares, os textos mais díspares. Eram os cegos quem se encarregava da venda e difusão destas edições económicas, ditas de «cordel» por causa das guitas (também chamadas barbantes) mediante as quais os folhetos eram pendurados aos braços dos vendedores ou à porta dos livreiros (Picchio, 1964, p. 196).

Estas obras não eram simplesmente traduzidas, mas adaptadas ao gosto português. Os livreiros tomavam a liberdade de fazer adaptações, extratar partes de obras completas, transferir a ação de cidades estrangeiras para portuguesas, mudar os nomes e suprimir certas cenas ou ampliando outras. Introduziam "novas personagens (criados e graciosos) destinadas a amenizar os textos, a torná-los aceitáveis a um público mais inclinado à farsa do que à tragédia" (Picchio, 1964, p. 198). O texto Roberto do diabo de Jeronymo de Carvalho é um dos que foi adaptado e impresso em versão de drama de cordel. A última impressão é de 1933, editada em Lisboa pela Livraria Barateira.

Numa antologia do Teatro Popular Mirandês - Textos de Cariz Profano, compilada pelo Gefac - Grupo de Etnografia e Folclore da Academia de Coimbra, descobrimos outra versão - esta em verso - com o título Verdadeira Tragédia do Roberto do Diabo (Gefac, 2003, p. 561-608). Neste poema dramático podemos encontrar, para além das falas do Duque e da Duquesa, ainda as deixas do Diabo,

Jangada | nr. 10, jul/dez, 2017 | ISSN 2317-4722 - 11 | 
com o nome de Lusbel. Aqui é ainda mais claro que Roberto é apenas o filho e não o Demónio. Roberto, pôde, depois ao longo de grande parte da sua vida, ter sido um terror e "o diabo em figura de gente", mas não é o Diabo:

\section{Duquesa}

Conceba ainda que seja

Agora aqui o Diabo

E o que eu conceber

Tudo lhe ofereço ao cabo

Que também tem grande poder.

$(\ldots)$

Quanto tenho falado

Que seja por ele aceite

Quero conceber o Diabo

E ao Diabo entrego o peito

$(\ldots)$

\section{Lusbel}

Grande festa tenho hoje

Pela Duquesa falar

Que me oferece seu peito

Para um filho gerar.

Eu lhe darei o poder

E ela um filho terá

Que será o terror de tudo

Quanto no mundo há.

Ele será meu servidor

E eu lhe darei o poder

Para conquistar o mundo

Ninguém o fará tremer (Gefac, 2003, p. 568).

Outros autores continuaram a interessar-se por este tema. Já no início do século XIX, Giacomo Meyerbeer (1791-1864), compositor alemão de seu nome completo Jakob Liebmann Meyer Beer, interessou-se pela lenda do duque da Normandia, compondo uma ópera em 5 atos, intitulada Robert le Diable. A ópera com libreto de Eugène Scribe (1791-1861) e Casimir Delavigne (1793-1843), estreou a 21 de novembro de 1831, na Ópera de Paris. Sete anos depois chegaria a Lisboa, tendo a sua estreia na capital portuguesa, no Real Teatro de São Carlos, no dia 2 de setembro de 1838, como citado por Sousa Bastos, em Carteira do Artista:

$$
\text { Jangada | nr. 10, jul/dez, } 2017 \text { | ISSN 2317-4722 - } 12 \text { | }
$$


Setembro 2

1838 - N'esta data, no Real Theatro de S. Carlos, sendo emprezario o Conde de Farrobo, subiu pela primeira vez á scena em Portugal, com grande esplendor, a notavel opera de Meyerbeer, Roberto o

Diabo, que causou grande enthusiasmo. Foi cantada por Santina Ferlotti, Claudia Ferlotti, João Paganini, Alexandre Zambaiti e Luiz Maggiorotti. O scenario foi pintado por Rambois e Cinatti (Bastos, 1898, p. 318).

Segundo Bastos o espetáculo terá colhido os maiores louros, causando grande entusiasmo, aos níveis artístico e plástico, exibindo enorme esplendor. Entretanto, vinte e cinco anos mais tarde, em 1863, foi a vez da cidade do Porto poder assistir à ópera em cinco atos do maestro Meyerbeer, no Real Teatro de S. João.

A lenda original de Robert le dyable, nascida logo no início do século XIII, vem suscitando algumas opiniões e interpretações, que a colocam entre a realidade e a ficção, como podemos observar no excerto que transcrevemos:

Outros críticos julgam a lenda como um eco longínquo das recordações sangrentas da invasão normanda, cujas devastações ainda não estavam totalmente esquecidas nos princípios do séc. XIII. Roberto não é portanto um personagem histórico ou totalmente histórico: é um tipo ideal dos bandidos medievais tomado dos duques descendentes dos ferozes piratas nórdicos. O terrível guerreiro, que passou depois a ser chamado Homem de Deus, é um símbolo personificado dos guerreiros da Idade Média com as suas paixões, crimes espantosos e suas sublimes virtudes. É a lenda um relato fantástico e devoto em que a misericórdia divina regenera a um monstruoso pecador, feito por arte diabólica em castigo do temerário e sacrílego pedido de sua mãe. O papa excomungou-o, o pai amaldiçoou-o, somente sua mãe procura regenerá-lo fazendo-o iniciar nas leis da cavalaria. Porém, ao entregar-se durante um torneio aos seus sanguinários instintos, vê-se abandonado de todos e

Jangada | nr. 10, jul/dez, 2017 | ISSN 2317-4722 - 13 | Pá g in a 


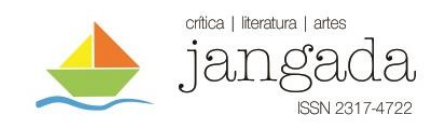

expulso de toda a parte. Mas um dia deteve-se a reflectir sobre a sua conduta. Procurou depois um santo ermitão a quem contou a sua vida e que lhe impôs a terrível penitência de se fingir mudo, passar por louco e não provar alimento sem o arrancar da boca de um cão. (...) Realizou, durante três anos, numerosas proezas sem se dar a conhecer, voltando depois a ser o pobre louco e mudo que serve de mofa ao populacho (Correia et al., 1981, p. 812).

A história medieval de Roberto, o diabo, foi sendo escrita e reescrita ao longo dos séculos e, como vimos, contada por trovadores e jograis e, destes últimos, por certo, a casta dos cazurros $^{3}$, ou seja, os bonecreiros, que a foram difundindo e adaptando. Esta terá sido, também, uma das peças do repertório clássico europeu de bonecos de luva.

Na citação acima, descobrimos nas adversidades de Roberto um sentimento trágico-cómico. O seu destino foi, ao longo da sua vida, ser manipulado, como um "boneco" pelas mãos das duas entidades sobrenaturais, Deus e Diabo (não obstante o direito de livre-arbítrio a que lhe assistia). Se virmos esta manipulação pela ótica cristã; primeiro foi tentado pelo Diabo, resultando da tentação a sua "depravada vida", para no fim, fruto de "seu grande arrependimento", ter obtido as graças de Deus.

Mas, a sua história também rapidamente se transformará em burlesco, se atendermos à passagem que diz que o castigo que o ermitão lhe atribuiu foi a de se fazer passar por mudo, louco e não comer nada se não tirada da boca a um cão. Há, de facto, neste episódio uma certa teatralidade e, Roberto do diabo reúne nesta passagem as características do ser malicioso, reservado e de poucas palavras, atribuídas ao caçurro.

A sua verosímil biografia, feito lenda, facilmente passou para a cena, concretamente para os retábulos dos bonecos daquele tempo, pelas mãos do jogral bonecreiro (caçurro). E para viver andava em constante itinerância, porque "o jogral

\footnotetext{
${ }^{3}$ Classificação dada por D. Afonso X de Leão e Castela aos bonecreiros. "La respuesta del rey, dada en 1275, distingue entre los istriones (tañedores de instrumentos), los inventores (trovadores) y los joculatores (acróbatas y jugadores de manos). As los truhanes denomina bufones, y a la clase más vil de representantes ambulantes, a los que hacían saltar a monos, machos cabríos o perros y hacían juegos de títeres, cazurros" (Varey, 1957, p. 10).
}

$$
\text { Jangada | nr. 10, jul/dez, } 2017 \text { | ISSN 2317-4722 - 14 | }
$$


é um profissional que não tem outras fontes de rendimento senão o seu trabalho de artista" (Saraiva, 1950, p. 127).

A história de Roberto do diabo remete-nos, deste modo, para o espírito endiabrado dos bonecos de luva tradicionais portugueses. Sendo assim, podemos daqui conjeturar que, vulgarizado o texto, em literatura de cordel, representado por fantoches, o público português tenha começado a chamar ao boneco de luva e às suas diabruras; Robertos. Verifica-se, assim, a evolução por um processo antonomástico, em que se deu a substituição de uma expressão (Roberto do diabo) por um nome que com ele tem afinidade semântica. Neste caso, generalizou-se o nome do título da obra pelo objeto de representação (o boneco).

Procurámos, entretanto, uma possível datação para o estabelecimento da denominação Roberto. Consultámos, para isso, o Diccionario do Theatro Portuguez, de Sousa Bastos, de 1908, onde são apresentados os "fantoches" e as "marionnettes", não havendo, no entanto, nenhuma alusão ao antropónimo em questão. Fomos, por isso, verificar os dicionários de etimologia e gerais da língua portuguesa, desde o Vocabulario Portuguez e Latino de Bluteau, de 1712, em diante. Nestes dicionários a primeira menção ao vocábulo Roberto surge no Grande Dicionário da Língua Portuguesa das Publicações Alfa, em 1991, onde se lê:

Roberto, adj. Açor. Travesso, trocista. \| Prov. alent. Madraço; relasso. || S. m. Fantoche (Machado, 1991, p. 542).

A escassez de registos escritos vem dificultar a obtenção de dados concretos que possam datar a vulgarização do termo Roberto. Todavia, se atendermos à referência feita aos Robertos por Matos Sequeira, chegamos às primeiras três décadas do século XX. Mas, qual seria a realidade vinte e cinco anos antes quando, em 1908, Sousa Bastos editou o seu Diccionario do Theatro Portuguez? A sua obra não alude aos Robertos, figurando nela unicamente referência às palavras fantoche e marionetas. O vocábulo não se havia vulgarizado no início do século e, teria já no tempo de Sousa Bastos, uma conotação negativa, considerado popularucho, de qualidade inferior, por se tratar de um boneco de luva tradicional, usado por titereiros

$$
\text { Jangada | nr. 10, jul/dez, } 2017 \text { | ISSN 2317-4722 - 15 | }
$$


populares, que atuavam nas praças, feiras e praias e não nos teatros convencionais. Encontramos aqui uma das justificações para a lacuna encontrada no dicionário de teatro, a comprovar pelo sentimento de qualidade inferior do teatro de robertos, transmitido nas palavras de Francisco Esteves, em 1964:

(...) a falta duma tradição entre nós de um teatro de bonifrates com o nível artístico superior ao que habitualmente se vê pelas feiras e nas praias no Verão (Esteves, 1964, p. 16).

A opinião manifestada por Esteves seria, pois, vulgar entre os intelectuais do início do século XX, levando a que o próprio Sousa Bastos tivesse tomado partido em relação a essa apreciação. Não obstante as razões que possam ter levado à omissão dos tradicionais bonecos de luva, estes foram fazendo parte dos poucos entretenimentos acessíveis às populações das classes sociais mais baixas. Os roberteiros eram, também, eles de origens humildes, cujos retábulos dos seus teatrinhos se resumiam a uma guarita, pequena barraca de ripas de madeira e tecido, onde atuavam os intrépidos robertos.

Voltemos, contudo, ao objeto da provável datação da terminologia Roberto. Recuemos até 1732, ano de edição da obra Roberto do diabo, com tradução de Jeronymo Moreira de Carvalho. Partindo do pressuposto de que este drama de cordel fez parte do repertório dos bonecos de luva portugueses, chegamos ao texto setecentista de Jeronymo de Carvalho. E, como vimos, os grandes textos de grandes autores foram adaptados e impressos em folhetos volantes e vendidos na rua a preços acessíveis. Destes fez parte o drama Roberto do diabo, cujo tema foi difundido pelos fantoches populares portugueses que, devido à dinâmica das atuações dos bonecos que integravam as peças de "pancadaria para animar" (Fonseca, 1966, p. 17), foram pelo povo batizados de Robertos $^{4}$.

\footnotetext{
${ }^{4}$ Os seus congéneres europeus têm, contudo, uma personagem principal, com nome próprio, contrariamente ao fantoche português que ficou conhecido pelo cognome plural, Robertos. Em 1962, Ernesto de Sousa (1921-1988), realiza o filme Dom Roberto, onde aparece uma guarita pintada com a designação "Teatro Dom Roberto", com uma ilustração de uma personagem dos filmes da Disney. Só a partir daí começam aos poucos a aparecer referências ao Dom Roberto.
}

Jangada | nr. 10, jul/dez, 2017 | ISSN 2317-4722 - 16 | 
A obra mais antiga onde pudemos identificar a nomenclatura em questão diz respeito ao Teatro de Outros Tempos de Matos Sequeira, datado de 1933. Deste modo e, na falta de documentação escrita com data anterior a esta, podemos inferir que a generalização do antropónimo Robertos terá tido a sua origem no início do século $\mathrm{XX}$.

\section{REFERÊNCIAS BIBLIOGRÁFICAS}

BAROJA, Julio Caro. Ensayo sobre la literatura de cordel. Madrid: ISTMO, 1990. BASTOS, Sousa. Carteira do Artista. Lisboa: José Bastos Editor, 1898.

CARVALHO, Jeronymo Moreira de. Historia do Grande Roberto, Duque de Normandia, e Imperador de Roma. Em que se trata da sua concepção, e nascimento, e de sua depravada vida, por onde mereceo ser chamado Roberto do diabo, e do seu grande arrependimento, e prodigiosa penitencia, por onde mereceo ser chamado Roberto de Deos, e prodigios, que por mandado de Deos obrou em batalha. Lisboa: $\mathrm{Na}$ Officina de Francisco Borges de Sousa. Com licença da Real Meza Censoria, 1799.

CORREIA, António Mendes et al. Grande Enciclopédia Portuguesa e Brasileira. Vol. XIII. Lisboa; Rio de Janeiro: Editorial Enciclopédia, 1981.

COSTA, J. Almeida; MELO, A. Sampaio e. Dicionário da Língua Portuguesa. Porto: Porto Editora, 2005.

ESTEVES, Francisco. É absolutamente necessário cultivar nas crianças o gosto pelo teatro. Jornal de Letras e Artes, Lisboa, p. 16, 11 de nov. 1964.

FONSECA, João Corregedor da. Teatro de Fantoches - Teatro de Rua: Uma tradição que se perde. O Século Ilustrado, Lisboa, p. 17, 23 abr. 1966.

FONSECA, João Corregedor da. Teatro de Fantoches - Teatro de Rua: Uma tradição que se perde. O Século Ilustrado, Lisboa, p. 17, 23 abr. 1966.

GAUCHER, Élisabeth. La vie du terrible Robert le dyable - Un exemple de mise en prose (1496). Le choix de la prose (XIII ${ }^{e}-X V^{e}$ siècles). Cahiers de Recherches Médiévales, Paris, 1998.

GEFAC - Grupo de Etnografia e Folclore da Academia de Coimbra. Teatro Popular Mirandês - Textos de Cariz Profano. Coimbra: Almedina, 2003.

MACHADO, José Pedro. Dicionário Etimológico da Língua Portuguesa. Vol. V. Lisboa: Livros Horizonte, 1995.

Jangada | nr. 10, jul/dez, 2017 | ISSN 2317-4722 - 17 | 
MACHADO, José Pedro. Grande Dicionário da língua Portuguesa.Vol. V. Lisboa: Publicações ALFA, 1991.

PICCHIO, Luciana Stegagno. História do Teatro Português. Lisboa: Portugália Editora, 1964.

SARAIVA, António José. História da Cultura em Portugal. Vol. I. Lisboa: Jornal do Fôro, 1950.

SEQUEIRA, Gustavo de Matos. Teatro de Outros Tempos: elementos para a História do Teatro Português. Lisboa: [s.n.], 1933.

SOARES, Maria Fernanda Martins; FERREIRA, Vítor Wladimiro. Grande Dicionário Enciclopédico Ediclube.Vol. XVI. Madrid: Ediclube, 1996.

VAREY, John Earl. Historia de los Títeres en España (Desde sus orígenes hasta mediados del siglo XVIII). Madrid: Revista de Occidente, 1957.

Jangada | nr. 10, jul/dez, 2017 | ISSN 2317-4722 - 18 | 